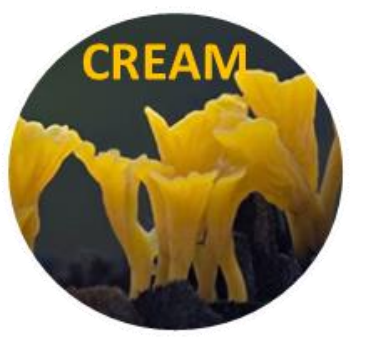

Current Research in Environmental \& Applied Mycology 5 (3): 196-201 (2015) ISSN 2229-2225

www.creamjournal.org

Article

CREAM

Copyright $@ 2015$

Doi 10.5943/cream/5/3/4

Online Edition

\title{
Potential role of host tree species in determining the composition of polysaccharides of Ganoderma lucidum (Fr.) Karst.(GLPS)
}

\author{
Singh $\mathbf{S}^{1^{*}}$, Harsh NSK ${ }^{2} \&$ Gupta PK $^{3}$
}

\author{
${ }^{1}$ Forest Pathology Division, Forest Research Institute, Dehradun,UK,India. Email: sona.singh13@ gmail.com \\ ${ }^{2}$ Forest Pathology Division, Forest Research Institute, Dehradun,UK,India \\ ${ }^{3}$ Cellulose \& Paper Division, Forest Research Institute, Dehradun,UK,India
}

Singh S, Harsh NSK, Gupta PK 2015 - Potential role of host tree species in determining the composition of polysaccharides of Ganoderma lucidum (Fr.) Karst.(GLPS). Current Research in Environmental \& Applied Mycology 5(3), 196-201, Doi 10.5943/cream/5/3/4

\begin{abstract}
Ganoderma lucidum is a basidiomycetous white rot fungus which has been used for medicinal purposes for centuries particularly in countries such as China, Japan and Korea. Several classes of bioactive substances have been isolated and identified from basidiocarp, mycelia and spores of $G$. lucidum, such as polysaccharides, triterpenoids, nucleosides, sterols, fatty acids, protein and alkaloids. One of the major pharmacological properties of G.lucidum is antitumor activity and polysaccharides (GLPS) are the main component responsible for this property. In this paper, the possible role of host tree species in determining the composition of polysaccharides (GLPS) was examined. To date, a careful comparison of polysaccharides (GLPS) from different host tree species has not been performed. Fruiting bodies were collected from nine host tree species from different regions of India and examined for their polysaccharide composition. These fruit bodies were analyzed and compared on the basis of Gas liquid chromatography (GLC). The result showed the fruit body from Dalbergia sissoo was most potential for GLPS production, as it was composed of all six tested monosaccharides, including rhamnose, arabinose, xylose, fructose, glucose and mannose. It also showed the presence of intense host-dependent variability among isolates.
\end{abstract}

Key words - anti-tumor activity - Dalbergia sissoo - gas liquid chromatography - host dependent variability - medicinal mushroom

\section{Introduction}

Ganoderma lucidum (Fr.) Karst. (Ganodermataceae) is a medicinal mushroom, belonging to the family polyporaceae. It is used as a popular medicine in China (named Ling Zhi) and Japan (named Reishi, Mannentake) for hundreds of years as a health tonic to promote longevity. It has been used for the treatment of a wide range of ailments and chronic diseases, such as migraine, hypertension, arthritis, bronchitis, asthma, anorexia, gastritis, haemorrhoids, diabetes, hypercholesterolaemia, nephritis, dysmenorrhoea, constipation, lupus erythematosis, hepatitis and cardiovascular problems. Importantly, it has been demonstrated by recent scientific studies to possess anticancer including leukemia, anti- ageing, anti- inflammatory and anti-microbial/viral activities, including anti-human immunodeficiency virus (HIV) activity (Gao et al. 2003). 
Pharmacological effect of G. lucidum is based on their powerful immune-modulating action and immune potential capability, which support and enhance the over all immune function, due to the presence of more than 200 active elements. Major elements include polysaccharide, triterpenoids, ptotrin, organic germanium, adenosine (Sanodiya et al. 2009).The highest attention is paid to polysaccharides from G. lucidum, which activate macrophages, lymphocytes, NK cells, proinflmmatory cytokines such as TNF or interleukins, essential for host survival from infection, and are also required for the repair of tissue injury (Gao et al. 2005).

Currently available data suggests that $G$. lucidum polysaccharides (GLPS), mostly $\beta$-glucanes, activate host's immune responses exerting anti-cancer functions, whereas anti-tumor effect of triterpenes seems to be related to their cytotoxic activity against the tumor cells directly (Wasser \& Weis 1999, Lin \& Zhang 2004, Kuo et al. 2006). It is also believed that G.lucidum acts as an immunological agent. It has been also used as a natural adjuvant for immunotherapy (Chan et al. 2005, Woźniak et al. 2012)

One of the most attractive properties of G. lucidum is anti-tumor effect which has been demonstrated to be mainly associated with its polysaccharides fraction by mediating immune system mechanisms (Sanodiya et al. 2009). Polysaccharides found in G. lucidum belong to $\beta$-glucan groups which according to Chan et al. (2008) is responsible for the stimulation of many kinds of immune response to prevent tumor formation

By keeping in view the medicinal importance, present study is focused on characterization of polysaccharides from different host tree species of G. lucidum. Increasing demand and nutraceutical significance of this fungus makes it necessary to explore the chemical diversity to open new prospects in natural product industry.

\section{Materials \& Methods}

Fruiting bodies of G. lucidum from nine different tree host species (Table 1) were used for the chemical analysis. All the experiments were conducted with triplicate and obtained data were subjected to analysis of variance (ANOVA) using SPSS 16.0.

\section{Drying of fruiting bodies}

Fruiting bodies were dried at $55^{\circ} \mathrm{C}$ for $4-5 \mathrm{~h}$ and then grounded to fine powder by using an electric grinder.

\section{Estimation of polysaccharides}

Polysaccharide estimation and identification was carried by preparation of alditol acetate followed by Gas Liquid Chromatography analysis.

\section{Hot water extraction}

Fruiting bodies were grounded to a fine powder using an electric grinder. Ten $g$ of the powder was boiled with $200 \mathrm{ml}$ of distilled water at $100^{\circ} \mathrm{C}$ for $3 \mathrm{~h}$. Mixture was cooled at room temperature and filtered through Whatman No.1 filter paper. Filtrate was then refluxed with two additional $100 \mathrm{ml}$ portions of distilled water. Filtrates (crude polysaccharides) were dried and used further (Bao et al. 2002).

\section{Complete hydrolysis}

Complete hydrolysis of crude polysaccharides (hot water soluble) was carried out (Soni and Srivastava, 1992). $0.2 \mathrm{~g}$ of crude polysaccharides was heated with $10 \mathrm{ml}$ of $12 \mathrm{M} \mathrm{H}_{2} \mathrm{SO}_{4}(2 \mathrm{~N})$ for $18 \mathrm{hr}$ produced a mixture of monosugars. Resulting hydrolysate was converted into its alditol acetate.

\section{Preparation of alditol acetates}

For the quantitative estimation of sugars, hydrolysates were converted into its alditol acetate by the method of Jansson et al. (1976). Gas Liquid Chromatography was carried out with a BP5, $0.25 \mathrm{~mm}$ capillary column $(30 \mathrm{~mm} \times 0.25 \mathrm{~mm})$, range- bipolar, temp $190-240^{\circ} \mathrm{C}$, pressuse- 2 bar and flow rate 
$1.5 \mu \mathrm{l} / \mathrm{min}$, run time $30 \mathrm{~min}$. Alditol acetate of authentic sugar mixture was also run under the same conditions to obtain the values of relative retention times (Rt).

\section{Results}

Fruiting bodies were powdered and their hot water extract prepared to isolate crude polysaccharides. Crude polysaccharides were hydrolyzed into their respective monosaccharides and converted into their alditol acetate for GLC analysis. Experimental results of GLC are summarized in Table 2 and Figs 1, 2.

It was apparent; all isolates were considerably different from each other in respect to presence of monosaccharides and their percentage. The predominant monosaccharides in these samples were Dmannose, D-galactose and D-glucose. D-rhamnose was present only in five samples i.e. Gl-55, Gl-7, Gl-34, Gl-45 and Gl-31. Maximum quantity of D-rhamnose was found in isolate no.Gl-34 (33.32\%) which was significantly superior to other isolates. D- arabinose was found in seven isolates Gl-15, Gl40, Gl-25, Gl-55, Gl-34, G1-45 and G1-31. Maximum amount of D-arabinose was found in isolate no.Gl-25 (33.07\%) which was statistically at par with isolate no.Gl-40 (32.67\%) and Gl-34 (31.75\%).

D-xylose was found in six isolates Gl-49, Gl-22, Gl-55, Gl-34, Gl-45 and Gl-31. Maximum quantity of D-xylose was found in Gl-22 (41.64\%). which was significantly superior to all the isolates. D-mannose was isolated from nine isolates Gl-49, Gl-15, Gl-22, Gl-40, Gl-25, Gl-55, Gl-34, Gl-45 and Gl-31and was not found in one isolate Gl-7. Isolate no. Gl-15 (55.17\%) has the maximum amount of D-mannose which was statistically at par with isolate no. Gl-45 (39.19\%). D-galactose was also found in nine isolates Gl-49, Gl-15, Gl-22, Gl-40, Gl-25, Gl-55, Gl-34, Gl-45 and Gl-31 and was absent in only one isolate no. Gl-7. D-glucose was present in eight isolates i.e. Gl-15, Gl-22, Gl-25, Gl-55, Gl-7, Gl-34, Gl-45 and Gl-31 and absent in two isolates i.e. Gl-49 and Gl-40. Maximum amount of Dglucose was found in isolate no. Gl-31 (61.89\%), collected from D.sissoo which was statistically superior to other isolates.

In these isolates, some sugars were present and some were absent. There were only four isolates in which all the six sugars were present i.e. Gl-55, Gl-34, Gl-45 and Gl-31. Isolate no. Gl-55 was collected from T. bellerica. Isolate no. Gl-34 and Gl-31 were from D. sissoo and isolate no. Gl-45 was from D. regia. On the basis of above mentioned chemical analysis (Table. 2), it was found that the fruiting bodies collected from $D$. sissoo showed the best values for various sugars in comparison to fruiting bodies collected from other host tree species. Among these, isolate no. Gl-31, showed the maximum quantity of D-glucose (61.89\%).

In this analysis, it was found that D-mannose and D-galactose were most frequent sugars, present in 9 isolates, whereas D-glucose was found in eight isolates only. At the same time, Darabinose was present in 7 isolates and D-xylose was present in 6 isolates. The least occurring monosaccharide was D-rhamnose, present only in 4 isolates.

On this basis, isolate no.Gl-31 from $D$. sissoo which has the maximum quantity of glucose $(61.89 \%)$ as well as also contains all the six monosugars was the most potent host tree species for polysaccharide (GLPS) production. From the above analysis (Table 2) it can be conferred that nature of host tree species affect the sugar composition of G. lucidum.

\section{Discussion}

Chemical diversity in context of host tree considered in present work was mainly focused on polysaccharides which attributed for the anticancerous properties of G.lucidum, reported by many researchers (Wasser 2002, Zhang et al. 2002, Zhang \& Lin 2004, Li et al. 2007, Zhang et al. 2007).Presence of different monosaccharides predominantly, D-mannose, D-galactose and D-glucose in fruiting bodies of G.lucidum was in conformity with the results mentioned by Zhang et al. (2002). In the current study, D. sissoo was found the most suitable host tree species for production G. lucidum polysaccharide (GLPS). It contains maximum quantity of glucose $(61.89 \%)$ as well as all other monosugars. The morphological and culture characters of all isolates were same but their polysaccharide composition was noticeably varies. The plausible reason for this difference was 
Table 1 List of fruiting bodies used for chemical study

\begin{tabular}{ccc}
\hline S. No. & Isolate No. & Host tree species \\
\hline 1 & Gl-49 & Mangifera indica L. \\
2 & Gl-15 & Ficus religiosa L. \\
3 & Gl-22 & Cassia siamea Lam. \\
4 & Gl-40 & Cassia fistula L. \\
5 & Gl-25 & Albizia lebbek Benth. \\
6 & Gl-55 & Terminelia bellerica Roxb. \\
7 & Gl-7 & Acacia nilotica L. \\
8 & Gl-34 & Dalbergia sissoo Roxb. \\
9 & Gl-45 & Delonix regia Raf. \\
10 & Gl-31 & Dalbergia sissoo Roxb. \\
\hline
\end{tabular}

climatic and nature of the host tree. The host tree on which the fungus grows saprophytically contributed in its chemical diversity. This fact was also supported by the findings Fernando 2008.

Observable variability was found in composition as well as in quantity of monosaccharide. This diversity was due to the effect of host on growth pattern of fruiting bodies. Isolates were selected according to their host tree species and it was observed that isolates from same host irrespective of their climate and location were less variable in polysaccharide contents, implying the presence of intense host-dependent variability. Similar observations were confirmed by Zakaria et al. (2009). It is evident from the above analysis that host tree plays a mojor role in determining the chemical composition. This study concludes that $D$. sissoo is the most preferable host of G. lucidum among the tested host tree for the production of polysaccharide (GLPS).

Table 2 Monosaccharides in the fruiting bodies of Ganoderma lucidum

\begin{tabular}{|c|c|c|c|c|c|c|}
\hline Isolates & D-rhamnose & D-arabinose & D-xylose & D-mannose & D-galactose & D-glucose \\
\hline Gl-49 & -- & -- & $\begin{array}{c}11.64 \\
(4.1)\end{array}$ & $\begin{array}{c}16.20 \\
(7.8)\end{array}$ & $\begin{array}{c}69.85 \\
(88.12)\end{array}$ & -- \\
\hline Gl-15 & -- & $\begin{array}{c}12.25 \\
(4.6)\end{array}$ & -- & $\begin{array}{l}55.17 \\
(67.3)\end{array}$ & $\begin{array}{c}20.92 \\
(12.87)\end{array}$ & $\begin{array}{l}22.91 \\
(15.2)\end{array}$ \\
\hline Gl-22 & -- & -- & $\begin{array}{l}41.64 \\
(44.2)\end{array}$ & $\begin{array}{l}24.13 \\
(20.0)\end{array}$ & $\begin{array}{l}10.85 \\
(3.56)\end{array}$ & $\begin{array}{l}32.18 \\
(29.5)\end{array}$ \\
\hline Gl-40 & -- & $\begin{array}{l}32.67 \\
(29.1)\end{array}$ & -- & $\begin{array}{l}25.30 \\
(18.5)\end{array}$ & $\begin{array}{l}43.28 \\
(47.0)\end{array}$ & -- \\
\hline Gl-25 & -- & $\begin{array}{l}33.07 \\
(29.8)\end{array}$ & -- & $\begin{array}{l}27.29 \\
(21.6)\end{array}$ & $\begin{array}{c}37.74 \\
(37.47)\end{array}$ & $\begin{array}{l}40.98 \\
(43.0)\end{array}$ \\
\hline Gl-55 & $\begin{array}{c}23.74 \\
(15.11)\end{array}$ & $\begin{array}{l}20.01 \\
(12.6)\end{array}$ & $\begin{array}{l}21.89 \\
(14.1)\end{array}$ & $\begin{array}{l}22.34 \\
(15.0)\end{array}$ & $\begin{array}{c}20.25 \\
(13.38)\end{array}$ & $\begin{array}{l}35.90 \\
(35.1)\end{array}$ \\
\hline Gl-7 & $\begin{array}{c}26.18 \\
(20.87)\end{array}$ & -- & -- & -- & -- & $\begin{array}{c}40.23 \\
(41.72)\end{array}$ \\
\hline Gl-34 & $\begin{array}{c}33.32 \\
(30.18)\end{array}$ & $\begin{array}{l}31.75 \\
(28.2)\end{array}$ & $\begin{array}{l}17.47 \\
(11.4)\end{array}$ & $\begin{array}{l}29.56 \\
(24.4)\end{array}$ & $\begin{array}{c}19.28 \\
(11.45)\end{array}$ & $\begin{array}{l}21.25 \\
(14.3)\end{array}$ \\
\hline Gl-45 & $\begin{array}{c}23.18 \\
(15.38)\end{array}$ & $\begin{array}{l}15.42 \\
(7.1)\end{array}$ & $\begin{array}{l}3.83 \\
(0.5)\end{array}$ & $\begin{array}{c}39.19 \\
(42.8)\end{array}$ & $\begin{array}{c}20.71 \\
(12.50)\end{array}$ & $\begin{array}{l}40.98 \\
(43.0)\end{array}$ \\
\hline Gl-31 & $\begin{array}{c}6.18 \\
(1.16)\end{array}$ & $\begin{array}{l}20.94 \\
(14.1)\end{array}$ & $\begin{array}{l}15.18 \\
(8.4)\end{array}$ & $\begin{array}{l}29.19 \\
(42.8)\end{array}$ & $\begin{array}{l}15.67 \\
(7.53)\end{array}$ & $\begin{array}{l}61.89 \\
(77.7)\end{array}$ \\
\hline $\begin{array}{c}\mathrm{CD} \text { at } 5 \\
\%\end{array}$ & 3.02 & 9.53 & 11.19 & 16.93 & 6.91 & 11.75 \\
\hline SEM & 4.47 & 5.44 & 7.70 & 8.07 & 10.48 & 8.05 \\
\hline
\end{tabular}

-- not present

Original values are given in parenthesis. 


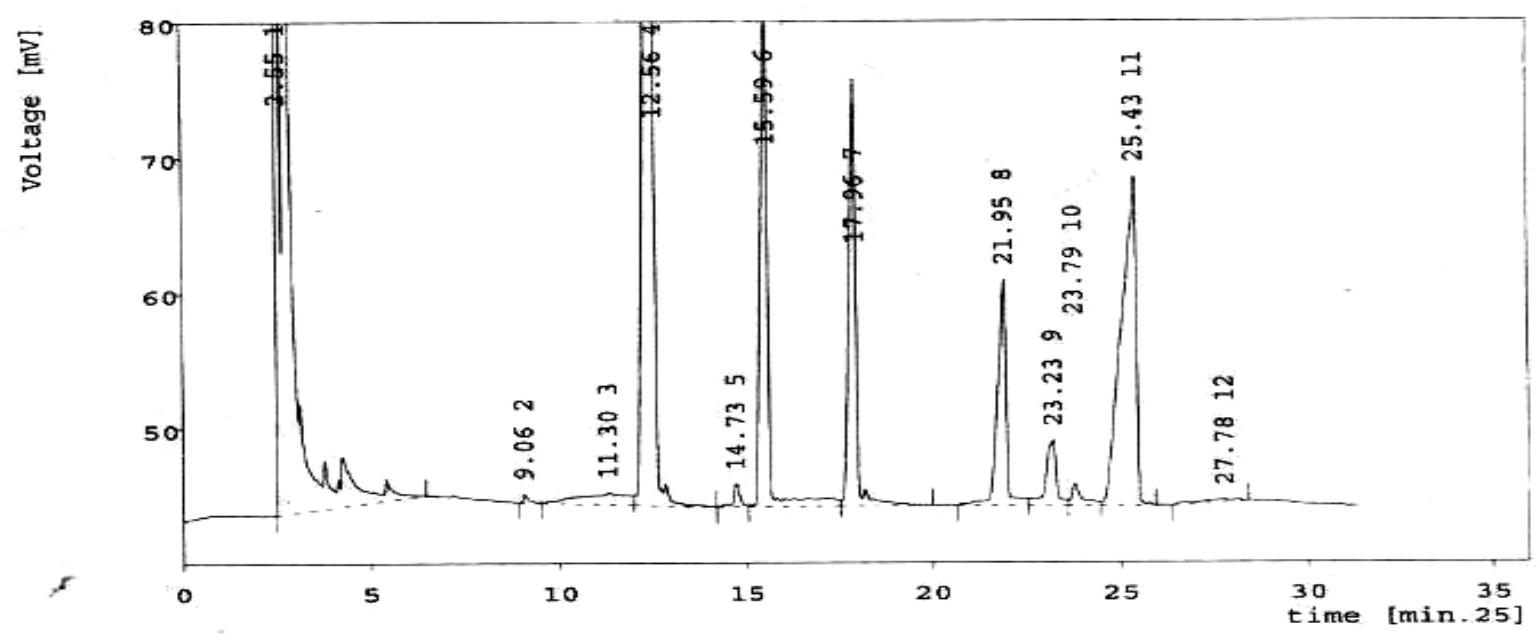

Fig.1-GLC graph of alditol acetate of six different standard sugars

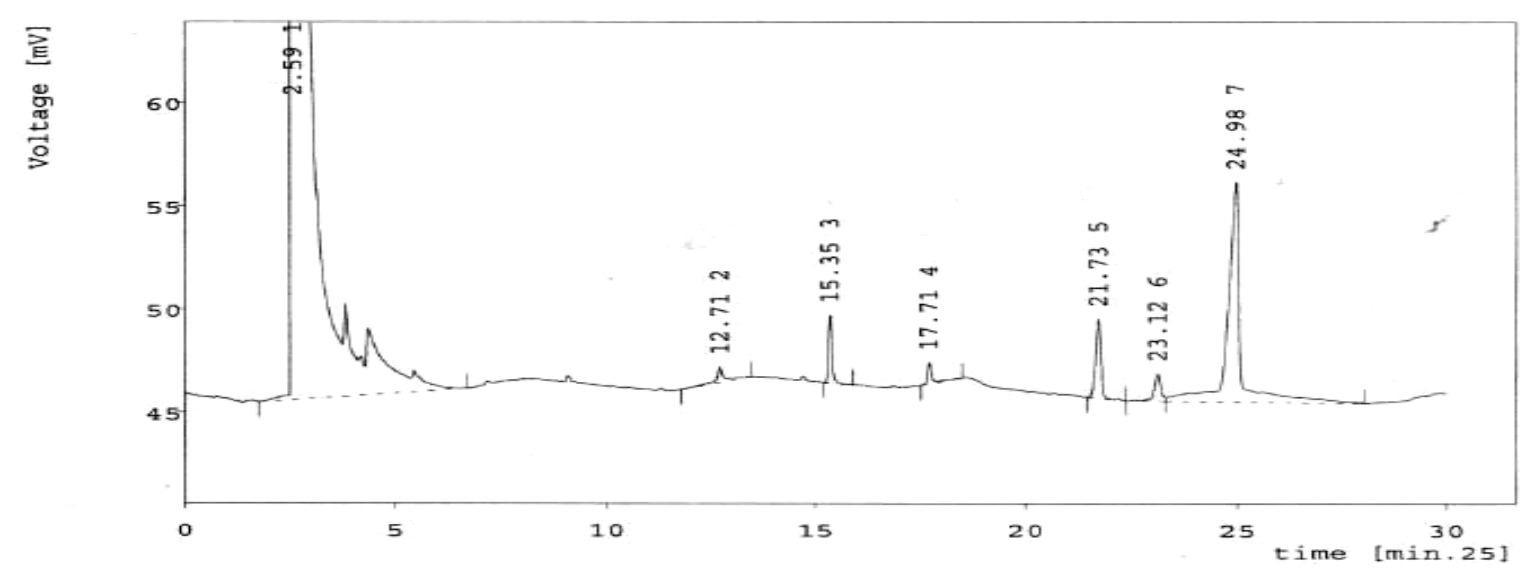

Fig. 2-GLC chromatograph of alditol acetate of isolate no. 31 of G.lucidum on D. sissoo

\section{Acknowledgements}

This work was financed by Forest Research institute, Dehradun, Uttarakhand, India.

\section{References}

Ahmadi K, Riazipour M. 2007- Effect of Ganoderma lucidum on cytokine release by peritoneal macrophages. Iranian Journal of Immunology 4, 220-226.

Bao XF, Wang XS, Dong Q, Fang JN, Li XY. 2002 - Structural features of immunologically active polysaccharides from Ganoderma lucidum Phytochemistry 59, 175-181.

Chan WK, Lam DTW, Law HKW, Wong WT, Koo MWL, Lau ASY. 2005 -Ganoderma lucidum mycelium and spore extracts as natural adjuvants for immunotherapy. Journal of Alternate Complement Medicine 11, 1047-1057.

Chan WK, Cheung CC, Law HK, Lau YL,Chan GC. 2008 -Ganoderma lucidum polysaccharides can induce human monocytic leukemia cells into dendritic cells with immuno-stimulatory function. Journal of Hematology and Oncology 1, 9.

Fernando KMEP. 2008 - The host preference of a Ganoderma lucidum strain for three tree species of Fabaceae family; Cassia nodosa, Cassia fistula and Delonix regia. Journal of the National Science Foundation of Sri Lanka 36, 323-326. 
Gao Y, Zhou S, Huang M, Xu A. 2003 - Antibacterial and antiviral value of the genus Ganoderma P. Karst. species (Aphyllophoromycetideae): A review. International Journal of Medicinal Mushroom 5, 235-246.

Gao Y, Gao H, Chan E, Tang W, Xu A, Yang H. 2005 - Antitumor activity and underlying mechanisms of ganopoly, the refined polysaccharides extracted from Ganoderma lucidum, in mice. Immunological Investigation 34, 171-198.

Huie CW, Di X. 2004 - Chromatographic and electrophoretic methods for Lingzhi pharmacologically active components. Journal of Chromatography B812, 241-257.

Jansson PE, Kenne L, Liedgren H, Lindberg B, Lönngren J. 1976 - A practical guide to the methylation analysis of carbohydrates. Chemical Communications University of Stockholm, 75pp.

Kuo MC, Weng CY, Ha CL, Wu MJ. 2006 - Ganoderma lucidum mycelia enhance innate immunity by activating NF-kappa B. Journal of Ethnopharmacology 103, 217-222.

Li YQ, Fang L, Zhang KC. 2007 - Structure and bioactivities of a galactose rich extracellular polysaccharide from submergedly cultured Ganoderma lucidum. Carbohydrate Polymers 68, 323-328.

Lin ZB, Zhang HN. 2004 - Anti-tumor and immunoregulatory activities of Ganoderma lucidum and its possible mechanisms. Acta Pharmacologica Sinica 25, 1387-1395.

Mahendran S, Anandapandian KTK, Shankar T, Chellaram C, Vijayabaskar P. 2012 - Antioxidant Properties of Ganoderma lucidum Crude Exopolysaccharide. Indian Journal of Innovations and Developments 1, 1-6.

Peng Y, Zhang L, Zeng F, Xu Y. 2003 - Structure and antitumor activity of extracellular polysaccharides from the mycelium of Ganoderma tsugae. Carbohydrate Polymer 54, 297-303.

Sanodiya BS, Thakur GS, Baghel RK, Prasad GBKS, Bisen PS. 2009 - Ganoderma lucidum: A Potent Pharmacological Macrofungus. Current Pharmaceutical Biotechnology 10, 717-742.

Soni PL, Srivastava HC. 1992 - Structural Polysaccharide Chemistry, Surya Publications, Dehradun, $12 \mathrm{p}$.

Wang CL, Lu CY, Pi CC, Zhuang YJ, Chu CL, Liu WH, Che CJ. 2012 - Extracellular polysaccharides produced by Ganoderma formosanum stimulate macrophage activation via multiple patternrecognition receptors. BMC Complementary and Alternative Medicine 12,119.

Wasser SP. 2002 - Medicinal mushrooms as a source of antitumor and immunomodulating polysaccharides. Applied Microbiology and Biotechnology 60, 258 - 274.

Wasser SP, Weis AL. 1999 -Therapeutic effects of substances occurring in higher Basidiomycetes mushrooms: a modern perspective. Critical Reviews in Immunology 19, 65-96.

Woźnia KS, Szypowski J, Los R, Siwulski M, Sobieralski K, Głowniak K, Malm A. 2012 -Evaluation of polysaccharides content in fruit bodies and their antimicrobial activity of four Ganoderma $\operatorname{lucidum}(\mathrm{W}$ Curt.: Fr.) P. Karst. strains cultivated on different wood type substrates. Acta Societatis Botanicorum Poloniae 81, 17-21.

Zhang HN, Lin Z. 2004 - Hypoglycemic effect of Ganoderma lucidum polysaccharides. Acta Pharmacologica Sinica 25, 191-195.

Zhang GL, Wang YH, Ni W, Teng HL, Lin ZB. 2002 -Hepatoprotectiverole of Ganoderma lucidum polysaccharide against BCG-induced immune liver injury in mice. World Journal of Gastroenterology 8, 728-733.

Zhang M, Cui SW, Cheung PCK, Wang Q. 2007 - Antitumor polysaccharides from mushrooms: a review on their isolation process, structural characteristics and antitumor activity. Trends in Food Science and Technology 18, 4-19.

Zakaria L, Kulaveraasingham H, Guan TS, Abdullah F, Wan HY. 2005 - Random Amplified Polymorphic DNA (RAPD) and Random Amplified Microsatellite (RAMS) of Ganoderma from infected oil palm and coconut stumps in Malaysia. Asia Pacific Journal of Molecular Biology and Biodiversity 13, 23-34. 